\title{
Estimation of Fixed Capital Investment in SMEs: the Existing Differentiation in the Russian Federation
}

\author{
Iuliia Pinkovetskaia, Vladislava Slepova \\ Ulyanovsk State University, Ulyanovsk, Russia
}

\section{Abstract}

Background: One of the goals of Russia economy is to increase SMEs specific weight in GDP per $100 \%$ by 2030 . Objectives: The purpose of this work is the assessment of the investments into fixed capital of SMEs and influence of factors such as size categories, types of economic activity and territorial placement, needed for the fulfillment of this goal. Methods/Approach: The comparative analysis of SMEs investments is based on relative indicators, which are calculated per enterprise and per worker. The research was conducted with the usage of the official statistical information obtained in the course of total observation of activity of the enterprises in 2015. Modelling of empirical data was based on functions of normal distribution. Results: We defined the values investments in SMEs which are located in 82 regions and related to three categories and six types of activity. We revealed regularities of distribution of investments calculated per enterprise and per worker, and identified the regions with the lowest investments in SMEs. Conclusions: New knowledge of the investment in the fixed capital in the Russian SMEs was achieved. Proposed information and tools are applicable for justification of the investments needed for the SMEs development. The methodical approach can be used in the future studies, as well in entrepreneurship and public management education.

Keywords: SMEs, size categories of the enterprises, investments into fixed capital, types of economic activity, regions of Russia

JEL classification: L26, C31

Paper type: Research article

Received: Nov 18, 2017

Accepted: Jan 13, 2018

Citation: Pinkovetskaia I., Slepova V. (2018), "Estimation of fixed capital investment in SMEs: the existing differentiation in the Russian Federation", Business Systems Research, Vol.9, No.1, pp. 65-78.

DOI: $10.2478 / \mathrm{bsrj}-2018-0006$

\section{Introduction}

SMEs(SMEs), as the accumulated experience shows, are the most important factor of economic development for many countries, including those in the conditions of economic crisis (Acs et al., 2008; Baumol, 2004; Decker et al., 2014; Simon-Moya et al., 2016). To date in Russia there are 5.6 million SMEs, which employ 18 million employees. SMEs produce $20 \%$ of Russia's gross domestic product. The share of 
Russian SMEs in the GDP and the number of employees is more than two times lower than the corresponding figures for the countries of the European Union (SME Bank, 2015).

In order to enhance the role and growth of SMEs, the state strategy for development of SMEs till 2030 was accepted (Russian Federation, 2016). The Strategy plans the growth of SMEs in GDP twice (up to 40\%) and growth of a share of workers in such enterprises up to $35 \%$ of the total number of the working population. The specified purposes, as shows foreign experience (Sollner, 2014), are real. Implementation of the strategy involves the formation of investment plans of the SMEs sector in the medium and long term.

The development of these plans should be based on the justification of investments into fixed capital. Therefore, an important scientific problem is to assess the relative levels of investment, namely investment per enterprise and per employee. Such relative indicators can provide the federal and regional authorities with the information needed to identify additional investments in fixed capital in the development of plans. This plans will be based on the anticipated increase in the number of enterprises and their workforce. The investment potential of SMEs should expand through the various forms and methods of investments attraction including such institutes as the state guarantees.

Government should provide information, marketing, financial and legal support to SMEs. To motivate the authorities on support of SMEs should be drawn up the official national rating of authorities' efficiency, based on the data of investment climate observations in the Russian regions. This rating must base on the comparative analysis mentioned above relative indicators through the regions. In Russia the system of incentives for development of SMEs in such regions should be created, where the role of entrepreneurship is low. The Korean experience of this activity is described in the article (Choi et al., 2015).

The purpose of the present paper is the assessment of the investments into fixed capital of SMEs in 2015 and influence of such factors as size categories, types of economy activity and territorial placement to them. In order to ensure a comparison of investments in SMEs located in different Russian regions, the calculations are based on the relative indicators. Fixed capital investments are determined in counting per one enterprise and per one employee. In our paper the modeling of differentiation of relative indicators of investment in SMEs in each of the regions is the bases for the application of functions of normal distribution. The possibility of applying such functions to describe relative performance follows the pilot work (Pinkovetskaia, 2015).

\section{Literature review}

Foreign and Russian authors researched the concepts and the principles of investment into fixed capital of SMEs. In our opinion, the following findings of researches are of the greatest interest. Pichler et al. (2000) gave the analysis of the main aspects of investment policy and factors, exerting impact on the amount of investment in the SMEs. Poire et al. (1984) proved on the case of Northern Italy, that in the circumstances of crisis small enterprises are more effective. That is why basic investment should be made into the SMEs, but not into the big enterprises with the standardized mass production. Skuras et al. (2008) discuss issues of justification of decisions on investments into fixed capital of SMEs of six countries of the European Union. The conclusion that the size of firm exerts direct impact on the volume of investment was drawn. Similar results are demonstrated by Lewandowska et al. (2015), who found out the significant differences in investments into SMEs in various 
regions of Poland. The China experience (Wu et al., 2008) demonstrates that the amount of investments depend on the types of activity in SMEs. In this article authors showed that to get the credit in the financial markets the enterprises must have specialists of this sphere. Microenterprises rarely employ such specialist, which creates a problem.

Regional aspects of investments into fixed capital of small enterprises in Russia are considered in the monograph (Gnevko, 2010), as the proof of essential distinctions of the volumes of investment in SMEs from territorial placement of these enterprises. Some articles are devoted to the study of investment in the SMEs of specific Russian regions. Bogomolova et al. (2016) analyzed investments into fixed capital of small business of the northern region and proved that they much depend on a type of economic activity. In another article, Noreen (2014) examined how the investments differ in East regions of Russia.

In general, the analysis of researches allowed us to draw a conclusion that problems of investment are relevant. Such factors as size categories, specialization of SMEs, and regions in which they are located, have significant effect on the amount of investments into fixed capital.

We propose the usage of the functions of normal distribution as the research tool. These functions have been widely disseminated in modern scientific research in the economy, engineering, medicine, psychology, biology. The following works can be cited as examples of using these functions in economic research. Allanson (1992) presented an analysis of the evolution of the size of agricultural land, including smallholder farming, based on the function density of distribution. In the book, Vince (1992) considered the application of normal distribution functions for the characteristics of trading activity and, in particular, the estimation of profits and losses. Filatov (2008) gives the main attention the method of complex assessment of the financial condition groups of enterprises. Totmianina (2011) proceeded from the normal distribution of the value of company assets, during the modeling of the probability of default of corporate borrowers of banks. Shapkin (2003) described approaches to portfolio investment management based on the normal distribution of equity returns. Modeling of financial profit in the Russian stock market is considered in the article Balaev (2014). Marek et al. (2013) discussed the possibility to predict the trend of the wage distribution. The determination of the number of empirical data is important in the development of normal distribution functions. The relevant justifications are presented in the works of various authors (Heinhold et al., 1964, Hodasevich, 2017), which indicated that the number of observations must be at least 40 . The quality of the developed normal distribution functions can be checked using tests. As showed the analysis of the literature (Bolshev et al., 1983; Hollender et al., 1983; Pearson et al. 1977; Shapiro et al., 1972) authors are using tests of Kolmogorov-Smirnov, Pearson and Shapiro-Wilk.

\section{Methodology}

The source of the data, used in this research, is official information of the Federal State Statistics Service of the Russian Federation gathered from so-called total observation of activity SMEs for 2015 (Federal State Statistics Service, 2017). Total observation included all SMEs, conducting activities in the territory of Russia. The division in size categories is made in accordance with Russian Federation state Law № 209 "About development of medium and small entrepreneurship in the Russian Federation". Information of observation includes indicators of activities of small enterprises (to 100 workers inclusive) and medium enterprises (from 101 to 250 
workers). Among small enterprises, there are identified microenterprises (up to 15 workers inclusive).

Statistical observation of SMEs in Russia was carried out on 14 types of economic activities: agriculture; fishery; mining and quarrying; processing productions; production and distribution of the electric power, gas and water; wholesale and retail trade; transport and communication; hotels and restaurants; operations with real estate; financial activity; education; health care; social and personal services. SMEs are located in all regions of Russia without exception. Therefore, these observations describe indicators of SMEs operating in 82 regions of Russia.

In the course of the research, two groups of SMEs had been defined. The first group included enterprises allocated on size and territorial features, and the second group - on type of economic activity and territorial features.

The enterprises located in each of 82 regions of Russia, belonging to the following three size categories, had entered into the first group: the microenterprises with the number of workers lower or equal to 15 , small enterprises with the number of workers from 16 to 100 persons, and medium enterprises numbering 101 to 250 workers.

We have also taken into account the specialized in six primary types of economic activity: agriculture; the processing productions; wholesale and retail trade; transport and communication; operations with real estate (Table 1). The exchange rate for 2015 in Russia was 1 ruble $=0,015$ Euros.

Table 1

Characteristics of SMEs, which related to the primary types of economic activity

\begin{tabular}{cccc}
\hline SMEs & $\begin{array}{c}\text { Volume of investment } \\
\text { into fixed capital, } \\
\text { billion rubles }\end{array}$ & $\begin{array}{c}\text { Number of } \\
\text { enterprises, } \\
\text { thousand units }\end{array}$ & $\begin{array}{c}\text { Number of } \\
\text { employees, } \\
\text { thousand persons }\end{array}$ \\
\hline $\begin{array}{c}\text { All enterprises of Russia, } \\
\text { including }\end{array}$ & 1348 & 1468 & 13517 \\
$\begin{array}{c}\text { Agriculture } \\
\text { Processing productions }\end{array}$ & 181 & 34 & 722 \\
\hline $\begin{array}{c}\text { Construction } \\
\text { Wholesale and retail trade }\end{array}$ & 159 & 146 & 2336 \\
$\begin{array}{c}\text { Transport and } \\
\text { communication }\end{array}$ & 109 & 162 & 1637 \\
Operations with real estate & 63 & 528 & 3342 \\
\hline $\begin{array}{c}\text { Six primary types of activity } \\
\text { Eight other types of activity }\end{array}$ & 380 & 101 & 252 \\
Source: Authors' work & 1195 & 347 & 11810 \\
\hline
\end{tabular}

The analysis of data from the Table 1 show that $88.6 \%$ of the total amount of investments are in fixed capital, $89.8 \%$ of the total number of enterprises and $87.4 \%$ of total employment concentrated in SMEs, belong to six primary types of economic activity. Respectively, the cumulative specific weight of investments in SMEs for eight other types of economic activity does not exceed $12 \%$. Specific weight of investments in SMEs for each of these eight types of economic activity does not exceed $2 \%$. Authors identified six primary types of activity for the following research, considering the prevalence of investments to the enterprises specialized on them.

In the course of the studies the following two hypotheses were tested:

- $\mathrm{Hl}$ : Relative investments per worker depend on the size category of the SMEs;

- H2: Relative investments per enterprise and per worker depend on the type of economic activity of SMEs. 
Distribution of values of the investments in SMEs calculated per enterprise and per worker across all regions can be described with application of the normal distribution. The following conceptual provisions define this.

Each SMEs act as the independent actor, defining the purposes and tasks, proceeding from a concrete situation, and conducts risk economic activity. Respectively, the group of the enterprises, formed on the criteria stated above, includes a significant amount of the enterprises. Economic, historical, climatic, demographic, educational and other features of development of the specific region in Russia have significant effect over SMEs sector indicators. This features act independently from each other, so we can assume probabilistic (stochastic) distribution of indicators values, including indicators of investments into fixed capital calculated per SMEs and per worker. Average investments per enterprise and per worker describe average arithmetic values for all SMEs in each region on three size categories and six types of activity.

Discussed in the paper investment in the fixed capital of SMEs formed by the influence of two kinds of drivers, the first of them determined the similarity of the investment values of regional groups of SMEs and the second their differences (Pinkovetskaia, 2015). The first type of drivers leaded to the investments grouping in the vicinity of some average value for all regions. The second type of drivers determined the degree of differentiation of investment values. The deviation of investments in specific regions from the average value could be both in the direction of reduction and in the direction of increase.

From the Chebyshev theorem (Kramer, 1962) follows that individual random values can have significant distinctions, in so doing, their arithmetic mean is relatively stable. A similar conclusion follows from the central limit theorem (Jenish et al., 2009), which establishes that the arithmetic mean of quite a large number of independent random values loses the character of a random value. Thus, the relative values of each SMEs investment in the region are random values that may have a significant spread, but we can foresee the significance of their arithmetic mean.

Note that in accordance with the Lyapunov theorem, the distribution of the average values of independent random values approaches the normal distribution, if the following conditions are met: all values have finite mathematical expectations and dispersion, none of the values is not sharply different from the rest. The mentioned above conditions correspond the values of relative investments in SMEs by regions. As Gmurman (2003) pointed out, the distribution of random values is fast enough (more than ten observations) approaching the normal distribution. The number of SMEs located in each region and related to specific size categories and types of economic activity ranges from hundreds to tens of thousands, which is much larger than the criterion by Gmurman (2003). In our paper, we used the methodical approach, which was based on the spatial data. Similar approach was considered in the work (Schröder et al., 2014).

Thus, there are theoretical prerequisites for using the functions of normal distribution to describe the differentiation of relative investments in the fixed capital of SMEs by regions of Russia. As already indicated in the literature review, considerable experience has been gained in using of normal distribution functions to describe the distribution of empirical indicators. In general course, the normal distribution function is as follows: 


$$
y(x)=\frac{K}{\sigma \cdot \sqrt{2 \pi}} \cdot e^{\frac{-(x-m)^{2}}{2 \cdot \sigma^{2}}}
$$

Where $m$ - average value; $\sigma$ - standard deviation; $K$-coefficient, which is determined by characteristics of random values and their dimensionality.

Thus, the estimation of values of investments in the fixed capital of SMEs, we gave in our paper, included the information on all enterprises in Russia and was based on functions of normal distribution. The assessment included the average values of SMEs investments in the Russian regions, which divided into three size categories and six types of economic activity. Investments were considered per enterprise (per worker), dispersion and interval of change, typical for most regions, as well as differentiation of investments on size categories of SMEs and types of activity.

Empirical information for 2015, which we used in the course of the research, included the volume of investments in fixed capital by SMEs, number of enterprises and number of employees. Values of investments we calculated, respectively per enterprise and per worker. We generated information for each region of Russia on three size categories and six types of economic activity. In total, we formed 18 informational databases. These databases included average values of fixed capital investments of SMEs located in each of 82 regions. As mentioned in the literature review theoretically, the research must have not low than 40 observations.

\section{Results}

We tested the formulated hypotheses using the data of relative investments of two groups of SMEs. The first group included SMEs of three size categories: medium enterprises, small enterprises, excluding microenterprises and microenterprises. The second group included SMEs of six primary types of economic activity: agriculture, processing productions, construction, wholesale and retail trade, transport and communication, operations with real estate. For SMEs that belong to each of the size categories and main types of activity were developed functions of normal distribution. These functions describe the distribution of values of investments in fixed capital counting per enterprise and per worker, for all SMEs located in each region of Russia. We developed 18 functions. Processing of statistical data and evaluation of functions of normal distribution were carried out with application of the Microsoft Excel 2010 and STATISTICA 10.

The indicators of the obtained functions of normal distribution are the average values of investments in fixed capital of SMEs for 2015, standard deviations, the intervals of change values of investment. These intervals correspond to the values of investments that are typical for SMEs located in the majority $(68 \%)$ regions of Russia. The boundaries of these intervals were determined on the basis of the average values of investments and standard deviations. The minimum value of the interval corresponds to the difference between the average investment value and standard deviation. The maximum value of the interval corresponds to the sum of the average investment value and standard deviation.

As the example, we presented three developed functions of normal distribution. They are describing the values of investment into fixed capital per enterprise (million rubles) for 2015.

The first function describes the distribution of investments per medium enterprise $\left(x_{i}\right)$ : 


$$
y_{1}\left(x_{1}\right)=\frac{685}{10,39 \times \sqrt{2 \pi}} \cdot e^{\frac{-\left(x_{1}-20,92\right)^{2}}{2 \times 10,39 \times 10,39}}
$$

It is well known that in a formula of function of normal distribution are such indicators as expected value (average value) and a standard deviation. In the formula (1) these values are equal to 20.92 and 10.39 respectively.

The second function describes the distribution of investments counting per small enterprise, excluding the microenterprises $\left(x_{2}\right)$ :

$$
y_{2}\left(x_{2}\right)=\frac{75}{1,21 \times \sqrt{2 \pi}} \cdot e^{\frac{-\left(x_{2}-2,45\right)^{2}}{2 \cdot 1,21 \times 1,21}}
$$

The third function describes the distribution of investments counting per microenterprise ${ }^{\left(x_{3}\right)}$ :

$$
y_{3}\left(x_{3}\right)=\frac{10}{0,16 \times \sqrt{2 \pi}} \cdot e^{\frac{-\left(x_{3}-0,34\right)^{2}}{2 \times 0,16 \times 0,16}}
$$

Tables 2 and 3 show the indicators that correspond to all developed functions of normal distribution on the three size categories and six basic types activity of SMES.

\begin{tabular}{|c|c|c|c|c|}
\hline $\begin{array}{c}\text { Number } \\
\text { of } \\
\text { function }\end{array}$ & Size categories & $\begin{array}{l}\text { Average } \\
\text { value }\end{array}$ & $\begin{array}{l}\text { Standard } \\
\text { deviations }\end{array}$ & Interval \\
\hline 1 & 2 & 3 & 4 & 5 \\
\hline \multicolumn{5}{|c|}{ Counting per enterprise } \\
\hline (2) & Medium enterprise & 20.92 & 10.39 & $10.53-31.31$ \\
\hline (3) & $\begin{array}{c}\text { Small enterprise excluding } \\
\text { microenterprises }\end{array}$ & 2.45 & 1.21 & $1.24-3.66$ \\
\hline (4) & Microenterprise & 0.34 & 0.16 & $0.18-0.50$ \\
\hline \multicolumn{5}{|c|}{ Counting per worker } \\
\hline (5) & Medium enterprise & 0.16 & 0.07 & $0.09-0.23$ \\
\hline (6) & $\begin{array}{c}\text { Small enterprise excluding } \\
\text { microenterprises }\end{array}$ & 0.08 & 0.03 & $0.05-0.11$ \\
\hline (7) & Microenterprise & 0.08 & 0.03 & $0.05-0.11$ \\
\hline
\end{tabular}

Table 2

Indicators of functions of normal distribution by three size categories, million rubles

Source: Authors' work 
Table 3

Indicators of functions of normal distribution by six types of activity, million rubles

\begin{tabular}{|c|c|c|c|c|}
\hline $\begin{array}{l}\text { Number of } \\
\text { function }\end{array}$ & Type of activity & $\begin{array}{l}\text { Average } \\
\text { value }\end{array}$ & $\begin{array}{l}\text { Standard } \\
\text { deviations }\end{array}$ & Interval \\
\hline 1 & 2 & 3 & 4 & 5 \\
\hline \multicolumn{5}{|c|}{ Counting per enterprise } \\
\hline (8) & Agriculture & 2.50 & 1.58 & $0.92-4.08$ \\
\hline (9) & $\begin{array}{c}\text { Wholesale and retail } \\
\text { trade }\end{array}$ & 0.13 & 0.07 & $0.06-0.20$ \\
\hline (10) & Construction & 0.99 & 0.64 & $0.35-1.63$ \\
\hline (11) & Processing industry & 0.68 & 0.36 & $0.32-1.04$ \\
\hline (12) & $\begin{array}{l}\text { Transport and } \\
\text { communication }\end{array}$ & 0.37 & 0.21 & $0.16-0.48$ \\
\hline (13) & $\begin{array}{c}\text { Operations with real } \\
\text { estate }\end{array}$ & 0.61 & 0.37 & $0.24-0.98$ \\
\hline \multicolumn{5}{|c|}{ Counting per worker } \\
\hline (14) & Agriculture & 0.24 & 0,12 & $0.12-0.36$ \\
\hline (15) & $\begin{array}{c}\text { Wholesale and retail } \\
\text { trade }\end{array}$ & 0.03 & 0.02 & $0.01-0.05$ \\
\hline (16) & Construction & 0.16 & 0.08 & $0.08-0.24$ \\
\hline (17) & Processing industry & 0.06 & 0.03 & 0.03-0.09 \\
\hline (18) & $\begin{array}{l}\text { Transport and } \\
\text { communication }\end{array}$ & 0.07 & 0.03 & $0.04-0.10$ \\
\hline (19) & $\begin{array}{c}\text { Operations with real } \\
\text { estate }\end{array}$ & 0.12 & 0.07 & $0.05-0.19$ \\
\hline
\end{tabular}

Source: Authors' work

The analysis of the dynamics of SMEs fixed investment from 2010 to 2015 showed that during this period in the calculation per enterprise they growth twice. The volume of production during the same period increased 2.3 times. Therefore, we suggested that the existing investments (the characteristics of which are shown in tables 1 and 2) were effective. Conservation the momentum of growth in investment is capable of further SMEs development. The assessment of the existing investments describes the regional averages of investments per enterprise and per worker, the size and the sector structure of investments and can be used to substantiate the need for investments for SMEs.

Testing of how well functions of normal distribution approximate the studied data, based on the application of criteria of consent, following from the theory of mathematical statistics. Authors used the tests of Kolmogorov-Smirnov, Pearson and Shapiro-Wilk. Tests allow to compare empirical distribution of the studied indicators with theoretical, described by the functions. Tests demonstrate the level of rejection of these data from the specified functions. The methodology of using tests detailed in the literature to which reference we gave in the literature review. In the table 4 we showed the calculated values, corresponding to the mentioned tests.

The calculated values of statistics by Kolmogorov-Smirnov test (provided in the second column of table 4) are from 0.3 to 0.10 , which is less than the table value that is 0.152 at a significance level of 0.05 . Similarly, the calculated values of the Pearson's test (given in the third column of table 4) are from 1.89 to 4.68, which is less than the value in the table equal to 9.49. Statistics value of the Shapiro-Wilk test (provided in the fourth column of table 2) is from 0.94 to 0.98 , which exceed the tabular value of 0.93 at a significance level of 0.01 . In general, the developed models have a high quality by all the tests and well describe the studied regularities. 
Table 4

Calculated values of statistics

\begin{tabular}{cccc}
\hline $\begin{array}{c}\text { Number of } \\
\text { function }\end{array}$ & \multicolumn{2}{c}{ Calculated value by criterion of consent } \\
\hline $\begin{array}{c}\text { by Kolmogorov- } \\
\text { Smirnov }\end{array}$ & by Pearson & by Shapiro-Wilk \\
\hline $\mathbf{1}$ & 2 & 3 & 4 \\
$(3)$ & 0,07 & 1,89 & 0,98 \\
$(4)$ & 0,06 & 2,39 & 0,97 \\
$(5)$ & 0,04 & 3,18 & 0,96 \\
$(6)$ & 0,05 & 2,73 & 0,97 \\
$(7)$ & 0,06 & 2,83 & 0,97 \\
$(8)$ & 0,04 & 3,92 & 0,95 \\
$(9)$ & 0,06 & 3,20 & 0,96 \\
$(10)$ & 0,04 & 4,31 & 0,95 \\
$(11)$ & 0,05 & 2,57 & 0,97 \\
$(12)$ & 0,10 & 2,57 & 0,96 \\
$(13)$ & 0,04 & 4,66 & 0,95 \\
$(14)$ & 0,03 & 4,52 & 0,95 \\
$(15)$ & 0,05 & 4,11 & 0,95 \\
$(16)$ & 0,06 & 3,92 & 0,95 \\
$(17)$ & 0,10 & 4,68 & 0,94 \\
$(18)$ & 0,07 & 3,30 & 0,95 \\
$(19)$ & 0,04 & 3,04 & 0,97 \\
\hline
\end{tabular}

Source: Authors' work

\section{Discussion}

Feature of functions of normal distribution (Venttsel, 2001) is that intervals of change of investments, characterize SMEs in most $(68 \%)$ regions. The boundaries of these intervals are calculated on the basis of the average values and standard deviations.

The data in table 2 show that the current level of investment in microenterprises ranges from 2700 to 7500 Euros per year (per enterprise) in most regions. These investments are not very large. That is why entrepreneurs can invest their money and the funds of their relatives. Therefore, microenterprises rarely use bank loans. In addition, microenterprises have no credit history and system of accounting, which banks need.

The data in table 2 show that the current level of investment in medium enterprises ranges from 150 to 460 thousand Euros per year (per enterprise) in most regions. These investments are significant. That is why medium enterprises often use bank loans. Medium enterprises possess the fixed assets; this allows them to get the credits under the security over property (this regularity was already earlier marked in the literature review). Besides, for the financial organizations more preferable provide credits to medium enterprises, than to small enterprises. This is because in the medium enterprises work specialists in crediting and they have ability to provide banks more complete information (including accounting information). This aspect of lending was described in the paper (Cook et al., 2000) devoted to questions on the information environment of the market investors.

Values of investments, which were counted per worker in small enterprises and the microenterprises, are the same. Investments counting per worker in medium enterprises much exceed this value in small enterprises (almost twice). Such provision sounds logical for a number of reasons listed further. Medium enterprises are 
technically best of equipped in comparison with small enterprises and, require larger costs of upgrade and support of production activity. Thus, the first hypothesis received a partial confirmation. Relative investments per worker in medium enterprises differ from small enterprises and microenterprises. The size of small enterprises has no effect on relative investments per worker. That is, in SMEs with a workforce of up to 100 people, relative investments do not depend on the size of the enterprise.

The characteristics of investments provided in table 2 are of interest as directly to the businessmen (especially start-ups) and to the departments of federal, regional and municipal government responsible for supporting business development. Besides, the credit and financial institutions, leasing and insurance companies, funds of guaranteeing and angel investors, could use this information.

The volumes of investment calculated per enterprise and per worker, significantly differ from region to region, that is visible from intervals of change given in columns 5 of tables 2 and 3. Values of investments could be used for monitoring of these values in regions, ratings analysis, marking regions with highest and lowest investments in SMEs. In addition, the results are capable to play an important role in addressing support to business by federal and regional authorities.

Regions of Russia with the least investments into fixed capital SMEs were defined from the minimum values corresponding to the lower bounds of intervals. In medium enterprises this group of regions represented by Yaroslavl, Ivanovo, Astrakhan, Sverdlovsk, Irkutsk, Kurgan, Tomsk regions, the city of Moscow and the republic of Dagestan. For small enterprises (excluding the microenterprises) low values of investments feature such regions as Moscow city, Murmansk, Novgorod, Sverdlovsk, Omsk and Tomsk regions, Zabaykalsky territory. For the microenterprises below of the interval, rated investment in Samara, Sverdlovsk, Kurgan, Omsk and Amur regions, the republics North Ossetia - Alania and Khakassia, Khabarovsk territory.

The relevant data could be used in course of developing ratings of investment climate in regions of Russia, projects and programs of business development, especially in regions where the level of investments into fixed capital is low.

Average values and intervals of change of the investments into fixed capital SMEs per different type of activity on the basis of data for 2015, are presented in table 3. We based them on the developed functions (8)-(19) describing investments into the enterprises specialized on six primary types of economic activity.

The data shown in table 3, present that the current level of investment in wholesale and retail trade SMEs is in the range from 900 to 3000 Euro per year (per enterprise), in transport and communication SMEs from 2400 to 7200 Euro per year (per enterprise). These investments are not very big, and entrepreneurs can implement them through personal funds and money of relatives. We found that the lowest investments are in trade enterprises and transport enterprises. It is caused by the following reasons. Small business in Russia began with trade enterprises and transport enterprises; they have gained bigger development in earlier years and they were on the peak of capital investments. Besides many trade enterprises represent the small outlets, which do not have much fixed capital. Similarly, transport entrepreneurs have several automobiles or buses.

The volumes of investments per enterprise and per worker much differ by types of economic activity that follows from the data provided in table 3. The highest level of investments into fixed capital of the enterprises is in the agricultural production. It is caused by great amounts of fixed assets of such enterprises. Besides, financial support of the agricultural enterprises through the state program of import substitution has considerably increased over recent years (Khulkhachieva, 2017). 
Agriculture SMEs need primarily bank loans. Big amounts of investments observed in construction industry are due to large volumes of housing construction by SMEs.

Thus, the second hypothesis was confirmed. That is, studies had shown that investments in fixed capital depend on the type of economic activity of SMEs.

The data provided in table 3 could be used for solving the problems of monitoring, planning and forecasting the volume of investment. Most relevant preparation of justifications on development of SMEs specialized on the types of activity, which have not gained enough development in specific regions of the country. The low level of investment is the characteristic of such regions. Values of the investment in SMEs are smaller, than the lower bounds of intervals (column 5 table 3). The carriedout analysis has shown that on the enterprises connected with agriculture, the lowlevel of investments noted in SMEs of such regions as the Astrakhan and Magadan regions, the republics of Komi, Dagestan, Tyva and Zabaykalsky territory. Insignificant investments into fixed capital of trade enterprises take place in the republics of Kalmykia, Ingushetia, Tyva, Sakha (Yakutia), Perm, Zabaykalsk, Primorsk, Khabarovsk territory, the Tomsk region. Below, than in other regions of Russia, investment into construction branch is in the Yaroslavl, Sverdlovsk, Omsk, Tomsk, Magadan regions. Investments into the processing industry are not enough in the Ivanovo, Arkhangelsk, Astrakhan, Tomsk, Omsk regions. In the SMEs of transport and communication, small investments are characteristic of the Ivanovo, Kursk, Volgograd, Samara, Sverdlovsk, Chelyabinsk and Novosibirsk regions. In the enterprises, which are carrying out operations with property the investment into fixed capital is low in such regions as the republics of Komi, Dagestan, Karachay-Cherkess and Kurgan regions.

\section{Conclusion}

In our research new knowledge of the amount of the investment in the fixed capital for the Russian SMEs was achieved. The research proves that the investments into fixed capital of SMEs depend on such factors as size categories of the enterprises, types of economic activity, and territorial placement of the enterprises. The most important results of researches are: (i) The first hypothesis was partially confirmed, and the second hypothesis was fully confirmed; (iii) We proved that investments into fixed capital significantly differ on the enterprises of various types of economic activity. At the same time, the agricultural enterprises need the greatest investments. The least investments characterize the trade enterprises; (iv) We defined regions, where the volumes of investment into fixed capital by each of size categories of the enterprises and primary types of economic activity, are characterized by values smaller, than the lower level of the corresponding intervals given in tables 2 and 3.

The acquired new knowledge can be used for further research, as well as in the training of students and entrepreneurs. The methodology and tools, which were used in the research process can be applied in the similar studies in the countries with a significant number of territorial (administrative) units.

We proposed the methodical approach and assessment tools for investment in SMEs, which can be useful in the research on entrepreneurship problems. The results received in this research, namely specific values of investments counting per enterprise and per worker, serve as a good reference points for the businessmen (especially for the start-up stage) and divisions of the state bodies responsible for the support of SMEs. Aspiring entrepreneurs can use the facts about investments per enterprise and per employee when they choose the type of activity. Working entrepreneurs, basing on the information provided in our paper, can plan further investments depending on the number of employees and the type of their economic activity. Financial institutions may use information to substantiate the 
granting of loans to SMEs, financing, leasing, factoring, consignment and other methods of investment. The authorities can apply the results of the study to substantiate plans of SMEs development.

The results of the simulation, namely minimum and maximum values of investments, can be used for monitoring and compiling the investment climate ratings in the regions of Russia. In addition, research results are needed to assess investment requirements for different groups of SMEs. They can be used to develop assistance programs for them, by providing SMEs with grants, subsidies, and reducing interest on loans. Government and regional authorities can use the research results to ensure the implementation of the Federal strategy for SMEs development for the period up to 2030 (Russian Federation, 2016).The future investigations are advised to be based on the information of investment in fixed capital of SMEs of various cities and municipalities.

\section{References}

1. Acs, Z., Desai, S., Hessels, J. (2008), "Entrepreneurship, economic development and institutions", Small Business Economics, Vol. 31, No. 3, pp. 219-234.

2. Allanson, P. (1992), "Farm size structure in England and Wales, 1939-89", Journal of Agricultural Economics, Vol. 43. No. 2, pp. 137-148.

3. Balaev, A. I. (2014), "Modelling Financial Returns and Portfolio Construction for the Russian Stock Market", International Journal of Computational Economics and Econometrics, Vol. 4, No. 1-2, pp. 32-81.

4. Baumol, W. J. (2004), "Entrepreneurial enterprises, large established firms and other components of the free-market growth machine", Small Business Economics, Vol. 23, No. 1, pp. 9-21.

5. Bogomolova, L. L., Takmasheva, I. V. (2016), "Economic evaluation of the structure of investments in fixed capital of small business of the northern region", Administration of Economic Systems: On-line research journal, No. 10, pp. 20-31.

6. Bolshev, L. N., Smirnov, N. V. (1983), Tables of mathematical statistic, Science, Moscow.

7. Choi, K. S., Choi, J. (2015), "Small and Medium Business and Investment Decision", Indian Journal of Science and Technology, Vol. 8, No. 24, pp. 1-6.

8. Cook, P., Nixson, F. (2000), "Finance and small and medium-sized enterprise development", University of Manchester, Finance and Development Research Programme Working Paper Series, Paper No 14.

9. Decker, R., Haltiwanger, J., Jarmin, R., Miranda, J. (2014), "The Role of Entrepreneurship in US Job Creation and Economic Dynamism", Journal of Economic Perspectives, Vol. 28, No. 3. pp. 3-24.

10. Federal State Statistics Service, (2017), Continuous observation of activity of small and medium business for 2015, available at http://www.gks.ru/free_doc/new_site/business/prom/small_business/itog2015/itogspn2015.html (29 August 2017)

11. Filatov, S. V. (2008), "Some questions of perfection methods of complex evaluation of condition enterprise", Economy, statistic and informatics, Journal UMO, MESI, No. 3. pp. 56-62.

12. Gmurman, V. E. (2003). Theory of probability and mathematical statistic, High school, Moscow.

13. Gnevko, V. A. (Ed.) (2010). Regional aspects of small business functioning and development of in Russia, Publishing House of St. Petersburg Academy of Management and Economics, St. Petersburg.

14. Heinhold, I., Gaede, K. W. (1964). Ingenieur statistic, Springer, München, Wien.

15. Hodasevich, G. B. (2017), "Work on the experimental data on EVM. Base definitions and operations work on the experimental data", available at: http://opds.sut.ru/old/electronic_manuals/oed/f02.htm (29 December 2017)

16. Hollender, M., Wulf, D. (1983). Nonparametric methods of statistic, Moscow. 
17. Jenish, N., Prucha, I. R. (2009), "Central limit theorems and uniform laws of large numbers for arrays of random fields", Journal of Econometrics, Vol. 150, No. 1, pp. 86-98.

18. Khulkhachieva, G. D. (2017), "The analysis of current trends and directions of the state support of agriculture of Russia in the conditions of the imposed bilateral sanctions", Bulletin of the NGIEl, Vol. 3, No. 70, pp. 134-142.

19. Kramer, G. (1962). Mathematical methods of statistic, Princeton University Press.

20. Lewandowska, A., Stopa, M., Hummenny, G. (2015), "The European Union Structural Funds and Regional Development. The Perspective of SMEs in Eastern Poland", European Planning Studies, Vol. 23, No. 4, pp. 785-797.

21. Marek, L., Vrabec, M. (2013), "Model wage distribution - mixture density functions", International Journal of Economics and Statistics, Vol. 1, No. 3, pp. 113-121.

22. Noreen, V. G. (2014), "Investments into small and medium business as factor of development of tor of the Far East of the Russian Federation", Improvement of mechanisms of development of innovative economy of Russia and its Far East territories: The collection of articles on materials of the international scientific and practical correspondence conference. Khabarovsk state academy of economy and right (Khabarovsk), pp. 85-90.

23. Pearson, E. S., D'Agostino, R. B., Bowmann, K. O. (1977), "Test for departure from normality: Comparison of powers", Biometrika, Vol. 64, No. 2, pp. 231-246.

24. Pichler, J. H., Pleitner, H. J., Schmidt, K. H. (2000). Management in KMU. Die Führung von Klein- und Mittelunternehmen, Haupt Verlag.

25. Pinkovetskaia, I. S. (2015), "Methodology of research indicators of work entrepreneurial structures", Works of Carel science centre RAN, No. 3. pp. 83-92.

26. Poire, M., Sabel, C. (1984). The Second Divide: Possibilities for Prosperity, Basic Books, New York

27. Russian Federation (2016), "The strategy of development of small and average business in the Russian Federation until 2030: Order of the Government of June 2, 2016 No. 1083r/Russian Federation Code", No. 24, Art. 3549.

28. Schröder, C., Yitzhak, S. (2014), "Reasonable sample sizes for convergence to normality", Berlin, SOEPpapers on Multidisciplinary Panel Data Research at DIW Berlin, No. 714, pp. 19.

29. Shapiro, S. S., Francia, R. S. (1972), "An approximate analysis of variance test for normality", Journal of the American Statistical Association, Vol. 67, No. 337, pp. 215-216.

30. Shapkin, A. S. (2003). Economica and financial risks. Estimation, management, investment portfolio", Moscow.

31. Simon-Moya, V., Revuelto-Taboada, L., Ribeiro-Soriano, D. (2016), "Influence of economic crisis on new SME survival: reality or fiction?", Entrepreneurship and Regional Development, Vol. 28, No. 1-2, pp. 157-176.

32. Skuras, D., Tsegenidi, K., Tsekouras, K. (2008), "Product innovation and the decision to invest in fixed capital assets: Evidence from an SME survey in six European Union member states", Research Policy. Vol. 37, No. 10, pp. 1778-1789.

33. SME Bank (2015). Development of small and average business, Foreign experience, Moscow.

34. Sollner, R. (2014), "The economic importance of small and medium-sized enterprises in Germany", Wirtschaft und Statistik, January, pp. 40-51.

35. Totmianina, K. M. (2011), "Review of models of probability of default", Management of financial risks, Vol. 1, No. 25, pp. 12-24.

36. Venttsel, E. (2001). Probability theory, The higher school, Moscow.

37. Vince, R. (1992). The Mathematics of Money Management: Risk Analysis Techniques for Traders, John Wiley \& Sons, New York.

38. Wu, J., Song, J., Zeng, C. (2008), "An Empirical Evidence of Small Business Financing in China", Management Research News, Vol. 31, No. 12, pp. 959-975. 


\section{About the authors}

Iuliia Pinkovetskaia graduated in 2006 at the Institute Economics and Business, Ulyanovsk State University, majoring in Mathematical methods in Economics. She gained a Ph.D. degree in Russia Academy of Entrepreneurship. She is currently employed as Associate Professor at the Department of Economic Analysis and State Management, Ulyanovsk State University. In 2014 and 2016, she has been awarded as the best young scientist (younger 35 years) in Ulyanovsk state university. From 2006 she teaches following courses: Statistics, State support of development entrepreneurship, Management of development clusters in regional economics, PR in the state sector, Management sociology, Economics of the city, State youth politics. Her main research fields include SMEs, investments, competition, innovations, management of economic systems, state and municipal management, mathematical modeling. She has published more than hundred papers in various national and international scientific journals and participated in scientific conferences. She can be contacted at pinkovetskaia@gmail.com

Vladislava Slepova graduated from the Faculty of Physics and Math in Ulyanovsk State Pedagogical University in 1993. A year later she was elected as an assistant in Economics and Management at the School of Economics and Management, Ulyanovsk State University. She gained her PhD in Economics from Ulyanovsk State University in 1997. In 2000/2001 she worked as a visiting professor at the Harry F. Byrd School of Business, Shenandoah University (Virginia, USA). From 2003 through 2010 she worked as head of department at the Government of Ulyanovsk region. Through these years she gained practical experience in SME policy development and implementation. Since 2011 she works for the Ulyanovsk State University as an Associate Professor of Public Administration. Her research fields include: social and economic development of region and municipality, territorial marketing, social cohesion. She teaches the following courses: state and municipal management, state decision making, and effectiveness audit. In 2013-2014 she joined the research group on social cohesion police development at the Council of Europe. She published number of scientific papers. She can be contacted at vlada_skuratova_73@mail.ru 